\title{
A NOVEL STUDY OF VALIDITY OF LATENT TUBERCULOSIS AS A PREDICTOR TO TUBERCULOSIS OF THORACIC SPINE
}

\author{
FAIQ I GORIAL ${ }^{1 *}$, MOHAMMAD YAHYA ABDULRAZAQ ${ }^{2}$, HAYDER ADNAN FAWZI ${ }^{3}$
}

${ }^{1}$ Department of Medicine, Rheumatology Unit, College of Medicine, University of Baghdad, Baghdad, Iraq. ${ }^{2}$ Consultant Pulmonologist, National Specialized Centre for Chest and Respiratory Diseases. Ministry of Health, Baghdad, Iraq. ${ }^{3}$ Department of Clinical Pharmacology, Baghdad Teaching Hospital, Baghdad, Iraq. Email: faiqig@gmail.com

Received: 10 November 2017, Revised and Accepted: 07 February 2018

ABSTRACT

Objective: The objective of this study is to assess the validity of latent tuberculosis (TB) as a predictor for TB of thoracic spine.

Methods: This cross-sectional study involved 31 patients with osteoarticular TB diagnosed on the base of clinical features, magnetic resonance imaging, and tissue biopsy. Patients' demographic and clinical characteristics of the disease were recorded. Latent TB was diagnosed by tuberculin skin test $($ TST) $>10 \mathrm{~mm}$.

Results: The mean age of patients was $44.9 \pm 19.0$ years. Females were 17 (54.8) and mean body mass index was $24.6 \pm 4.9 \mathrm{~kg} / \mathrm{m}^{2}$. Thoracic spine was the highest osteoarticular TB site. Then, lumbar spine TB was $3(9.7 \%)$ patients. Third in rank was TB of the knee joints 2 (6.5\%). Cervical spine and hip joint TB were each one, 1 (3.2) patients, respectively. Validity of latent TB as a test to predict TB of thoracic spine revealed that if TST was positive, then this test will be accurate in $77.42 \%$ and we can establish the diagnosis of TB of the thoracic spine with $90.48 \%$ confidence if we had a clinical suspicion of TB of thoracic spine.

Conclusion: There was a significant positive correlation between osteoarticular TB and latent TB. Thoracic spine TB was the most common osteoarticular TB infection compared to other sites. Patients who had latent TB have 9.5 times risk of having TB of the thoracic spine. Latent TB was a valid measure to predict TB of thoracic spine.

Keywords: Latent tuberculosis, Osteoarticular tuberculosis, Tuberculosis

(c) 2018 The Authors. Published by Innovare Academic Sciences Pvt Ltd. This is an open access article under the CC BY license (http://creativecommons. org/licenses/by/4. 0/) DOI: http://dx.doi.org/10.22159/ajpcr.2018.v11i9.26676

\section{INTRODUCTION}

Tuberculosis (TB) is a multisystemic chronic infection caused by Mycobacterium TB and considered a major global health issue worldwide with 8.8 million people developing TB annually $[1,2]$. Drug-resistant TB developed due to improper treatment or interruption of treatment [3], and according to the latest WHO estimate, it ranks as the second leading cause of death from an infectious disease worldwide after the human immunodeficiency virus. Most of the estimated number of cases in 2011 were reported in Asia (59\%) and Africa (26\%) [4]. Osteoarticular TB is an uncommon form of extrapulmonary TB (EPTB) and comprises 1-6\% of all TB cases and $10-15 \%$ of all EPTB cases $[5,6]$. Osteoarticular TB can cause significant morbidity, and a high index of suspicion is needed for early diagnosis so as to avoid destruction and disability [7]. Even with adequate medical and surgical treatment, osteoarticular TB can be associated with morbidity and mortality [8]. EPTB usually takes the form of arthritis or osteomyelitis. Rarely. it can present as tenosynovitis or bursitis. The common sites of involvement are spine and weightbearing joints. Studies available on extrapulmonary TB, with reference to incidence and bacteria positivity, are scarce [9]. Musculoskeletal TB has been infrequently reported, especially in the developed world [10].

Latent TB infection (LTBI) is characterized by the presence of immune responses to Mycobacterium TB infection without clinical evidence of active TB $[11,12]$. A vast majority of infected persons have no signs or symptoms of TB disease and are not infectious, but they are at risk for developing active TB disease and becoming infectious [13]. The tuberculin skin test (TST) is widely used and inexpensive test to diagnose latent TB, but it has poor specificity and sensitivity [14]. Up to knowledge, there was no previous study on correlation between osteoarticular TB and latent TB. This study was designed to assess the correlation between osteoarticular TB and latent TB.

\section{PATIENTS AND METHODS}

\section{Study design}

This cross-sectional study was conducted in outpatient clinics in Baghdad Teaching Hospital and National TB specialized center, Baghdad, Iraq, from June 2016 to December 2016. Ethical approval was taken from the Department of Medicine, College of Medicine, University of Baghdad, and an informed written consent was obtained from each patient participated in the study.

\section{Sample selection}

Patients included in the study were those with any age and sex with TB osteoarticular diagnosed according to clinical and laboratory investigation and proved with tissue biopsy that was referred to the outpatient clinics in National TB specialized center.

\section{Data entry, collection, and evaluation}

Data were collected using questionnaire and interview with the patients who were seen consecutively. Sociodemographic and clinical data were collected and included age, sex, body mass index, history of contact with TB, history of pulmonary TB, smoking history, history of comorbid diseases like diabetes, renal impairments, and history of immune suppressants intake.

\section{Outcome measurements}

Latent TB was diagnosed by TST in millimeters [15], and TB site location was determined by magnetic resonance imaging (MRI).

TST was done by an intradermal injection of 2TU of Statens Serum Institut (SSI) tuberculin RT23 in $0.1 \mathrm{ml}$ solution for injection. The reaction will be read 48 to 72 hours later and we measure the diameter of induration across the forearm in millimeters. If there is no induration, 
the result should be recorded as " 0 mm" A test $>10 \mathrm{~mm}$ was considered positive for our patients $[16,17]$.

\section{Statistical analysis}

Anderson darling test was done to asses if continuous variables follow a normal distribution. All variables follow normal distribution which were expressed as mean \pm standard deviation. Categorical variables were presented using numbers and percentage. Difference between categorical variables was measured using Fisher's exact test. Binary logistic regression analysis was used to assess the relationship between latent TB and TB site. SPSS 20.0.0 and Minitab 17.1.0 were used to perform the statistical analysis, $\mathrm{p}<0.05$ was considered statistically significant.

\section{RESULTS}

Mean age of the patients was $44.9 \pm 19.0$ years ranging from 10 to 70 years, while mean BMI $24.6 \pm 4.9 \mathrm{~kg} / \mathrm{m}^{2}$ ranging from 15.53 to 34.37 , and females were $54.8 \%$. Other clinical characteristics are shown in Table 1.

The highest prevalence of osteoarticular TB was thoracic spine TB 24 patients $(77.4 \%)$ as shown in Fig. 1.

Fig. 2 shows that prevalence of patients with thoracic spine TB who had latent TB was significantly higher than other TB of other locations (19 [79.2\%] vs. 2 [28.6\%], p=0.022).

Patients with latent TB (TST>10 mm) had significantly higher risk of having thoracic TB compared to those patients who did not have latent TB. Latent TB increases the risk of having thoracic spine TB by 9.5 times as shown in Table 2.

Validity of latent TB as a test to predict TB of thoracic spine revealed that if TST was positive, then this test will be accurate in $77.42 \%$ and we can establish the diagnosis of TB of thoracic spine with $90.48 \%$ confidence if we had clinical suspicion of TB of thoracic spine as shown in Table 3

\section{DISCUSSION}

This cross-sectional study showed a significant positive correlation between osteoarticular TB and latent TB. Thoracic spine TB was the most common osteoarticular TB infection compared to other sites. Patients who had latent TB had 9.5 times risk of having TB of thoracic spine. This finding is clinically important and suggests that patients with latent TB have a high risk of osteoarticular TB infection, especially TB spine. Therefore, patients with latent TB will give us high index of suspicion of the early diagnosis and appropriate treatment of TB spine to prevent its neurological complications or spinal deformity instability.

This osteoarticular TB may be caused by reactivation of bacilli lodged in bone during the original mycobacteria of primary infection. The predilection of the bacillus for the spine and large joints may be related to the heavy vascular supply of the vertebra and growth plates of the long bones. Furthermore, it is believed to result from extension of a primary infectious focus in the bone to the joint. And it is Infrequently to be just: Tuberculous bacilli travel from the lung to the spine along the Batson paravertebral venous plexus or by lymphatic drainage to the paraaortic lymph nodes [17].

Similar to the current study, Pigrau-Serrallach and Rodríguez-Pardo reported that tuberculous vertebral osteomyelitis affects the thoracic or thoracolumbar segment in around half of the cases, followed by the lumbar segment, and to a much lesser extent, the cervical segment [18].

Some studies observed that TB spine was the most common site of articular TB. TB spine was reported to be $64 \%$ in Mateo et al. study [19] and 49\% in Houshian et al. study [20]. Other studies showed that multifocal non-contiguous spinal involvement is reported to be
Table 1: Demographic and clinical features of the patients

\begin{tabular}{ll}
\hline Variables & Values \\
\hline Age (years), mean \pm SD (range) & $44.9 \pm 19.0(10-70)$ \\
BMI $\left(\mathrm{kg} / \mathrm{m}^{2}\right)$ & $24.6 \pm 4.9(15.53-34.37)$ \\
Gender n(\%) & $14(45.2)$ \\
$\quad$ Male & $17(54.8)$ \\
Female & $2(6.5)$ \\
History of TB contact n(\%) & $2(6.5)$ \\
History of pulmonary TB infection n(\%) & $3(9.7)$ \\
Immunosuppressant use n(\%) & $5(16.1)$ \\
Diabetes history n(\%) & $2(6.5)$ \\
Ischemic heart disease history n(\%) & $5(16.1)$ \\
Hypertension n(\%) & $1(3.2)$ \\
Renal impairment n(\%) & $18(58.1)$ \\
Smokers n(\%)
\end{tabular}

BMI: Body mass index, TB: Tuberculosis, SD: Standard deviation, n: Number, $\%$ : Percent

Table 2: Logistic regression analysis to assess the correlation between thoracic spine TB and latent TB

\begin{tabular}{lcc}
\hline Variable & OR 95\% CI & p value \\
\hline TST positive & $9.51 .403-64.346$ & 0.021 \\
\hline $\begin{array}{l}\text { Binary logistic regression, OR: Odd ratio, 95\% CI: 95\% Confidence interval, } \\
\text { TB: Tuberculosis }\end{array}$
\end{tabular}

Table 3: Validity of latent TB as a predictor to TB of thoracic spine

\begin{tabular}{llllcl}
\hline Parameter & Sensitivity & Specificity & Accuracy & PPV & NPV \\
\hline $\begin{array}{l}\text { Latent TB } \\
\text { positive (\%) }\end{array}$ & 79.17 & 71.43 & 77.42 & 90.48 & 50 \\
\hline
\end{tabular}

PPV: Positive predictive value, NPV: Negative predictive value, TB: Tuberculosis

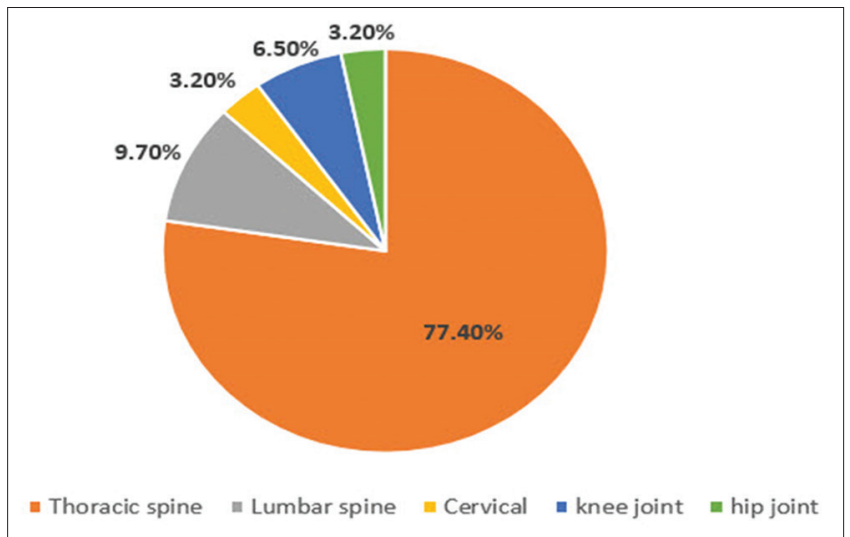

Fig. 1: Osteoarticular distribution of tuberculosis

uncommon and observed in $16.3-71.4 \%$ of cases when whole-body MRI is performed [21-23]. It was more common in areas that have a high prevalence of mycobacterial infection, such as South Africa [23]. However, the risk of having TB of the thoracic spine if they had latent TB and its validity as a predictor for TB of thoracic spine was not reported in the previous studies.

The main limitation of the present study was a small sample of patients and may be solved by a larger prospective study; however, it is the first study that reports a correlation between osteoarticular TB and latent TB.

In conclusion, osteoarticular TB significantly associated with latent TB and those patients with latent TB had a high risk of having thoracic spine $\mathrm{TB}$, and latent TB is a valid measure for predicting TB of thoracic spine. 


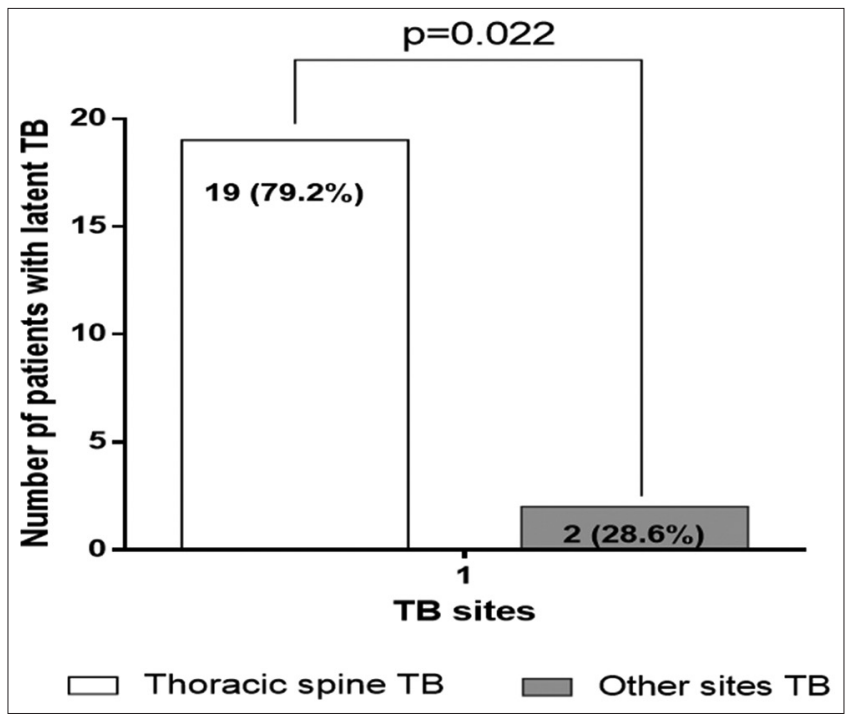

Fig. 2: Comparison between thoracic spine tuberculosis (TB) and other sites according to the presence of latent TB

This suggests that screening for latent TB may help in prediction of osteoarticular TB and early diagnosis and subsequently better treatment response with prevention of spinal and neurological complications.

\section{AUTHOR'S CONTRIBUTIONS}

All authors were involved in drafting the article or revising it critically for important intellectual content, and all authors approved the final version to be published. Dr. Gorial had full access to all of the data in the study and took responsibility for the integrity of the data and the accuracy of the data analysis.

Study conception and design: Faiq I. Gorial, Mohammad YahyaAbdulrazaq, and Hayder Adnan Fawzi.

Acquisition of data: Faiq I. Gorial and Mohammad Yahya Abdulrazaq.

Analysis and interpretation of data: Faiq I. Gorial, Mohammad Yahya Abdulrazaq, and Hayder Adnan Fawzi.

\section{CONFLICTS OF INTEREST}

All the authors hereby declare that there is no conflict of interest.

\section{REFERENCES}

1. Sajith M, Thomas A, Kothia JJ, Chandrakar B, Pawar A, Bargaje MD. Cost of therapy incurred for tuberculosis patients receiving directly observed therapy (DOT). Int J Pharm Pharm Sci 2015;7:141-4.
2. Moura AC, Mosegui GB, Vianna CM, Cordeiro BC. Cost-effectiveness analysis of directly observed therapy for tuberculosis and its expansion in Rio De Janeiro Int J Pharm Pharm Sci 2017;9:171.

3. Hasan S, Saeed S. Conventional and recent diagnostic aids in tuberculous lymphadenitis: A brief overview. Asian J Pharm Clin Res 2017; $10: 85-8$

4. World Health Organisation. Global Tuberculosis Report 2012. Ch. 2. In: The burden of Disease Caused by TB. Geneva: WHO; 2012. p. 8-22.

5. Houston A, Macallan DC. Extrapulmonary tuberculosis. Medicine 2014;42:18-22.

6. Hong L, Wu JG, Ding JG, Wang XY, Zheng MH, Fu RQ, et al. Multifocal skeletal tuberculosis: Experience in diagnosis and treatment. Med Mal Infect 2010;40:6-11.

7. Chauhan A, Gupta BB. Spinal tuberculosis (Letters to the editor). JIACM 2007;8:110-4

8. Muangchan C, Nilganuwong S. The study of clinical manifestation of osteoarticular tuberculosis in Siriraj hospital, Thailand. J Med Assoc Thai 2009;92 Suppl 2:S101-9.

9. Yoon HJ, Song YG, Park WI, Choi JP, Chang KH, Kim JM, et al. Clinical manifestations and diagnosis of extrapulmonary tuberculosis. Yonsei Med J 2004;45:453-61.

10. Sagoo RS, Lakdawala A, Subbu R. Tuberculosis of the elbow joint. JRSM Short Rep 2011;2:17.

11. World Health Organization. Guidelines on the Management of Latent Tuberculosis Infection. Geneva: WorldHealth Organization; 2015.

12. Mack U, Migliori GB, Sester M, Rieder HL, Ehlers S, Goletti D, et al. LTBI: Latent tuberculosis infection or lasting immune responses to M. Tuberculosis? A TBNET consensus statement. Eur Respir J 2009;33:956-73.

13. Getahun H, Matteelli A, Chaisson RE, Raviglione M. Latent Mycobacterium tuberculosis infection. N Engl J Med 2015;372:2127-35.

14. O'Garra A, Redford PS, McNab FW, Bloom CI, Wilkinson RJ, Berry MP, et al. The immune response in tuberculosis. Annu Rev Immunol 2013;31:475-527.

15. Abdulrazaq MY. Latent tuberculosis infection is still a big challenge for tuberculosis control. Iraqi New Med J 2016;2:63-8.

16. The Mantoux Test. Administration, Reading and Interpretation. NHS. $\mathrm{UK} ; 2017$.

17. Gardam M, Lim S. Mycobacterial osteomyelitis and arthritis. Infect Dis Clin North Am 2005;19:819-30.

18. Pigrau-Serrallach C, Rodríguez-Pardo D. Bone and joint tuberculosis. Eur Spine J 2013;22 Suppl 4:556-66.

19. Mateo L, Ruiz Manzano J, Olivé A, Manterola JM, Pérez R, Tena X, et al. Ostearticular tuberculosis. Study of 53 cases. Med Clin (Barc) 2007;129:506-9.

20. Houshian S, Poulsen S, Riegels-Nielsen P. Bone and joint tuberculosis in Denmark: Increase due to immigration. Acta Orthop Scand 2000;71:312-5.

21. Jain AK. Tuberculosis of the spine. J Bone Joint Surg (Br) 2010;92B:905-13

22. Kaila R, Malhi AM, Mahmood B, Saifuddin A. The incidence of multiple level non-contiguous vertebral tuberculosis detected using whole spine MRI. Eur Spine J 2009;18:1096-101.

23. Polley P, Dunn R. Noncontiguous vertebral tuberculosis detected using whole spine MRI. J Spinal Disord Tech 2007;20:78-81. 